www.jmscr.igmpublication.org

Impact Factor 5.84

Index Copernicus Value: 71.58

ISSN (e)-2347-176x ISSN (p) 2455-0450

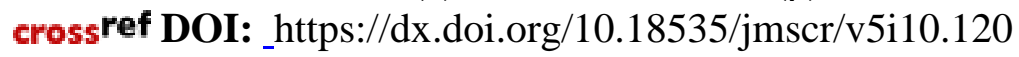

Journal Of Medical Science And Clinical Research

IGM Publication

An Official Publication of IGM Publication

\title{
Prevalance of Cognitive Dysfunction in Elderly Patients Attending a Tertiary Care Teaching Hospital in Puducherry
}

\author{
Authors \\ Suhaim Latif Perumbadi, M K Uthaya Sankar, Arun S \\ Sri Manakula Vinayagar Medical College and Hospital, Kalitheerthalkuppam, Puducherry 605107 India \\ Corresponding Author \\ Suhaim Latif Perumbadi \\ Department Of General Medicine, Sri Manakula Vinayagar Medical College and Hospital \\ Kalitheerthalkuppam, Puducherry 605107 India \\ Mob: 9626611990, Email: suhaim.perumbadi@gmail.com
}

\begin{abstract}
Elderly population are one of the most vulnerable and major age group of individuals in our population. The rising rate of cognitive diseases such as Alzheimer's disease, senile dementia and other psychiatric ailments among this age group is of great concern to the treating physician as well as, a burden in the society and the family of the individual. In this study we evaluated the prevalence of cognitive impairment among the elderly individuals in a tertiary care hospital in Puducherry to cumulate the bulk of patients that may be developing any form of cognitive dysfunction among the apparently mentally healthy elderly individuals. A Mini-Mental State Exam questionnaire was used to assess the individuals and score them into categories of cognitive health. We found that 19.3\% of our patients had a cognitive dysfunction. This shows the bulk of silent cases of cognitive dysfunction ns that prevail among our elderly patients which warrants an expert evaluation and care in order to improve or support their lifestyle and hence reduce the burden of geriatric health problems in society. We also tried to correlate this impairment to their lifestyle and comorbidities but could not get a statistically significant result for the same, hence imparting the need for further larger scale studies.
\end{abstract}

Key Words: Cognitive dysfunction, Alzheimer's disease, MMSE, Geriatric health.

\section{Introduction}

In light of the continuing rise in the population of elderly individuals of impaired cognitive function diminishing one's quality of life, accurate and effective screening for early recognition and differentiation between normal age-related cognitive declines, mild cognitive impairment (MCI), mild Alzheimer's disease, and other causes of cognitive decline is in much need. The MiniMental State Examination (MMSE) is one of the most widely used tools implemented by physicians to evaluate a patient's cognitive status. Common use among physicians occurs because the MMSE provides a bedside screening test of cognitive impairment in hospitalized patients. The MMSE's feasibility in terms of the time required to administer a test to assess a patient's degree of cognitive impairment, as opposed to longer mental status tests or neuropsychological batteries makes it a popular tool among physicians. 
The objective of this study was to screen for cognitive dysfunction among old age patients admitted to a tertiary care teaching hospital in Puducherry.

\section{Aims \& Objectives}

1) To screen for cognitive dysfunction among old age patients.

2) To compare the cognitive functioning of elderly patients with co morbidities like hypertension and diabetes.

3) To compare the cognitive functioning of elderly patients with lifestyle habits such as alcohol consumption and smoking.

\section{Materials \& Methods}

Setting: Hospital based

Study design: Questionnaire based prospective study

Study participants: 55 to 85 year old attendees of a tertiary care hospital in Puducherry

Study duration: 3 months

Sample size: $160(4 \mathrm{pq} / \mathrm{d} 2$, where $\mathrm{p}=38.3, \mathrm{q}=$ 61.7 and $d=$ relative precision of $20 \%$ )

Inclusion criteria: Subjects 55 to 85 years old

\section{Exclusion criteria}

- Subjects diagnosed with clinical depression or other psychiatric illness

- Use of psychoactive medications known to significantly affect memory (particularly anxiolytics and hypnotics)

- Presence of a confounding central neurologic disease (e.g., brain tumour, stroke, epilepsy)

Any patient admitted to Sri Manakula Vinayagar Medical College and Hospital fitting the sample criteria was assessed with a physical and neurological examination to rule out any confounding neurologic disease and enrolled in an MMSE evaluation following which they were scored for the presence of cognitive impairment and severity. This was further compared to the presence of comorbidities such as Type 2 diabetes mellitus and/or hypertension or substance habits such as smoking and/or alcohol intake.
Any patient found to have significant cognitive dysfunction were further for further expert neurological and psychiatrically evaluation.

\section{Data entry and analysis}

The data was entered in Microsoft Excel and analysed using EpiData analysis software. The continuous variables such as age and MMSE scores were summarized as mean (SD). The categorical variables including sociodemographic, behavioural and clinical conditions were summarized as proportions. The key outcome cognitive impairment was expressed as proportion with $95 \% \mathrm{CI}$. The association between study participants characteristics and cognitive impairment was estimated using odds ratio with $95 \%$ CI. $P$ value of $<0.05$ was considered as statistically significant.

\section{Results}

Table 1. Socio demographic, behavioural factors and chronic disease characteristics of study participants:

\begin{tabular}{|c|c|}
\hline $\begin{array}{l}\text { Socio demographic } \\
\text { characteristics }\end{array}$ & $\begin{array}{c}\text { Number of participants } \\
(\%) \\
\mathrm{N}=161\end{array}$ \\
\hline Age in years - Mean (SD) & $64.5(7.0)$ \\
\hline \multicolumn{2}{|l|}{ Sex } \\
\hline Male & $83(51.6)$ \\
\hline Female & $78(48.4)$ \\
\hline \multicolumn{2}{|c|}{ Educational status } \\
\hline Illiterate & $51(31.7)$ \\
\hline Primary school & $80(49.7)$ \\
\hline Higher secondary & $12(7.5)$ \\
\hline Pre university & $6(3.7)$ \\
\hline Graduate & $12(7.5)$ \\
\hline \multicolumn{2}{|c|}{ Socio economic status } \\
\hline Socio economic status II & $22(13.7)$ \\
\hline Socio economic status III & $63(39.1)$ \\
\hline Socio economic status IV & $75(46.6)$ \\
\hline Socio economic status V & $1(0.6)$ \\
\hline \multicolumn{2}{|c|}{ Smoking status } \\
\hline Absent & $126(78.3)$ \\
\hline Present & $35(21.7)$ \\
\hline \multicolumn{2}{|c|}{ Alcohol intake } \\
\hline Absent & $113(70.2)$ \\
\hline Present & $29(29.8)$ \\
\hline \multicolumn{2}{|c|}{ Hypertension } \\
\hline Present & $47(29.2)$ \\
\hline Absent & $114(70.8)$ \\
\hline \multicolumn{2}{|c|}{ Type 2 diabetes mellitus } \\
\hline Present & $57(35.4)$ \\
\hline Absent & $104(64.6)$ \\
\hline
\end{tabular}


In our study we found $31(19.3 \%)$ of our study group of 161 patients to have a cognitive dysfunction by MMSE scoring. Out of these cases 2 of the patients had a severe cognitive cognitive dysfunction while all others were of minimal cognitive dysfunction (Table 2).
Table 2. Presence of cognitive impairment and MMSE scores of the study participants:

\begin{tabular}{|l|c|}
\hline & $\begin{array}{c}\text { Number of participants } \\
\mathbf{N}=161 \\
\mathbf{n}(\boldsymbol{\%})[\mathbf{9 5 \%} \text { CI] }\end{array}$ \\
\hline \multicolumn{2}{|c|}{ Cognitive impairment } \\
\hline No impairment & $130(80.7)[74.0-86.1]$ \\
\hline Mild impairment & $29(18.1)[12.8-24.7]$ \\
\hline Severe impairment & $2(1.2)[0.3-4.4]$ \\
\hline
\end{tabular}

Table 3 Association between patient characteristics and the presence of cognitive impairment among them:

\begin{tabular}{|c|c|c|c|c|c|}
\hline $\begin{array}{l}\text { Study } \\
\text { participants } \\
\text { characteristics }\end{array}$ & $\begin{array}{l}\text { Total } \\
\text { n }(\%)\end{array}$ & $\begin{array}{c}\text { Cognitive } \\
\text { impairment } \\
\text { present } \\
\mathrm{N}=31 \\
\mathbf{n}(\%)\end{array}$ & $\begin{array}{c}\text { No cognitive } \\
\text { impairment } \\
\mathrm{N}=130 \\
\mathrm{n}(\%)\end{array}$ & OR $(95 \% \mathrm{CI})$ & P value* \\
\hline $\begin{array}{l}\text { Age in years } \\
\text { Mean (SD) }\end{array}$ & 161 & $67.2(7.8)$ & $63.9(6.6)$ & - & 0.017 \\
\hline \multicolumn{6}{|c|}{ Sex } \\
\hline Male & $83(51.6)$ & $11(13.3)$ & $72(86.7)$ & 1 & \multirow[t]{2}{*}{0.046} \\
\hline Female & $78(48.4)$ & $20(25.6)$ & $58(74.4)$ & $2.26(1.00-5.09)$ & \\
\hline \multicolumn{6}{|c|}{ Education } \\
\hline Illiterate & $51(31.7)$ & $8(15.7)$ & $43(84.3)$ & 1 & \\
\hline Primary school & $80(49.7)$ & $20(25.0)$ & $60(75.0)$ & $1.79(0.72-4.45)$ & 0.205 \\
\hline Higher secondary & $12(7.5)$ & $2(16.7)$ & $10(83.3)$ & $1.08(0.20-5.86)$ & 0.933 \\
\hline Pre university & $6(3.7)$ & $1(16.7)$ & $5(83.3)$ & $1.08(0.11-10.47)$ & 0.950 \\
\hline Graduate & $12(7.5)$ & $0(0.0)$ & $12(100.0)$ & - & 1.000 \\
\hline \multicolumn{6}{|c|}{ Socio economic status } \\
\hline SES - 2 & $22(13.7)$ & $2(9.1)$ & $20(90.0)$ & 1 & \\
\hline SES -3 & $63(39.1)$ & $20(31.7)$ & $43(68.3)$ & $4.65(0.99-21.86)$ & 0.037 \\
\hline $\mathrm{SES}-4 \& 5$ & $76(47.2)$ & $9(11.8)$ & 67 (88.2) & $1.19(0.23-6.08)$ & 0.831 \\
\hline \multicolumn{6}{|c|}{ Smoking } \\
\hline Smoker & $35(21.7)$ & $6(17.1)$ & $29(82.9)$ & $0.84(0.31-2.23)$ & \multirow[t]{2}{*}{0.720} \\
\hline Non smoker & $126(78.3)$ & $25(19.8)$ & $101(80.2)$ & 1 & \\
\hline \multicolumn{6}{|c|}{ Alcohol } \\
\hline Alcoholic & $29(29.8)$ & $7(14.6)$ & $41(85.4)$ & $0.63(0.25-1.59)$ & \multirow[t]{2}{*}{0.327} \\
\hline Non alcoholic & $113(70.2)$ & $24(21.2)$ & $89(78.8)$ & 1 & \\
\hline \multicolumn{6}{|c|}{ Hypertension } \\
\hline Present & $47(29.2)$ & $10(21.3)$ & 37 (78.7) & $1.20(0.51-2.78)$ & \multirow[t]{2}{*}{0.676} \\
\hline Absent & $114(70.8)$ & $21(18.4)$ & $93(81.6)$ & 1 & \\
\hline \multicolumn{6}{|c|}{ Type 2 diabetes mellitus } \\
\hline Present & $57(35.4)$ & $13(22.8)$ & 44 (77.2) & $1.41(0.63-3.14)$ & \multirow[t]{2}{*}{0.397} \\
\hline Absent & $104(64.6)$ & $18(17.3)$ & $86(82.7)$ & 1 & \\
\hline
\end{tabular}

\section{Discussion}

The purpose of this study was to identify the presence cognitive impairment among patients of elderly age group admitted in Sri Manakula Vinayagar Medical College, Puducherry and to observe any correlation between the same and comorbid conditions or substance abuse.

A total of 161 patients were assessed among whom 31 patients $(19.3 \%)$ were found to have any cognitive dysfunction of which 2 had severe cognitive impairment and others were of mild cognitive dysfunction by MMSE scoring.

The mean age of patients assessed was 64.5 years among an almost gender neutral study group (83 males and 78 females). Females had a higher incidence of cognitive dysfunction with $25.6 \%$ participants testing for abnormal MMSE scores while only 13.3 males had the same. Both of the 2 
participants who had severe cognitive dysfunction were females.

Most of the subjects were of primary school education $(49.7 \%)$ and contributed 20 of the 31 cases tested positive for cognitive impairment. Illiterates were the next largest group (31.7\%) and made up 8 out of the 31 cognitively impaired cases. Only $3.7 \%$ were of pre-university level education and had only 1 patient to test positive among them. Higher secondary school and degree graduate level were both of $7.5 \%$ with 2 cases of cognitive dysfunction in higher secondary education group and none from the degree graduate group. This was not statistically significant. In an analysis by Evans et al, the effect of education on risk for disease remained approximately the same. ${ }^{1}$

Majority of our study group cases belonged to lower socio economic status making $46.6 \%$ of patients belong to class 4 socio economic group and $0.6 \%$ belonged to the lowest, class 5 socio economic group; amongst them 9 of them were found to have a cognitive dysfunction. Class 3 patients made $39.1 \%$ of the population and had 20 of them testing positive for cognitive dysfunction. The remaining $13.7 \%$ were of class 2 socio economic status and 2 of them had cognitive dysfunction. These results were also not statistically significant. There were no patients belonging to class 1 in our study. In an elaborate study by Holzer et al, the socio economic status relationship varied among psychiatric disorders, with the strongest relationships occurring for cognitive impairment and schizophrenia. ${ }^{2}$

$21.7 \%$ of patients were smokers and $29.8 \%$ of the participants had history of regular alcohol intake either in past or at present. Out of all the 31 cases found to have cognitive dysfunction, 6 of them were smokers and 7 of them took alcohol. All of them were males. These results were statistically not significant. Smoking was found to be a prospective risk factor for incident cognitive impairment in a study by Cervilla et al, but there was no association to alcohol found in the same study. $^{3}$
$29.2 \%$ of the participants had history of hypertension and $35.4 \%$ had type 2 diabetes mellitus. 10 hypertensives and 13 diabetics were among the 31 cases of cognitive dysfunction found in our study. These results were also not statistically significant. Findings by Knopman et aland Elias et al are consistent with the general conclusion that BP-associated performance deficits are relatively minor and manageable in terms of everyday functioning. Elias et al further contributed that higher baseline BP levels and JNC classifications are predictive of cognitive decline in Visualization/Fluid abilities. ${ }^{4}$ Kodl et al in their study in patients with type 2 diabetes identified an increase in memory deficits, a reduction in psychomotor speed, and reduced frontal lobe/executive function. ${ }^{5}$

As seen in most studies, the correlation between cognitive impairment and factors such as comorbidities, substance abuse and education were not significant in our study as the study group was not large enough and hence warrants further studies to be carried out on a larger scale. This was an institution based study of a short duration which has exposed the risk of cognitive dysfunction in the apparently normal elderly individuals.

\section{Conclusion}

This study throws light on the existence of silent cognitive impairment existing among the apparently mentally healthy elderly individuals in our population

This may lead to poor quality of life and progressive psychiatric or organic disease which can be controlled or prevented by routine screening and early intervention.

This calls for a cognitive screening towards all elderly patients attending a medical facility for any ailment. In order to better recognize and alleviate the burden of geriatric health issues and also better utilize the expert treatment options available to them.

Larger scale and better sophisticated studies are necessary in order to find correlations between the 


\section{JMSCR Vol||05||Issue||10||Page 29165-29169||October}

existence of these impairments with that of factors such as education status, substance abuse and comorbid conditions in order to target individuals at higher risk of acquired cognitive defects.

\section{Reference}

1. Evans DA, Beckett LA, Albert MS, Hebert LE, Scherr PA, Funkenstein HH, Taylor JO. Level of education and change in cognitive function in a community population of older persons. Annals of epidemiology. 1993 Jan 1;3(1):71-7.

2. Holzer CE, Shea BM, Swanson JW, Leaf PJ. The increased risk for specific psychiatric disorders among persons of low socioeconomic status. American Journal of Social Psychiatry. 1986.

3. Cervilla JA, Prince M, Mann A. Smoking, drinking, and incident cognitive impairment: a cohort community based study included in the Gospel Oak project. Journal of Neurology, Neurosurgery \& Psychiatry. 2000 May 1;68(5):622-6.

4. Elias MF, Goodell AL, Dore GA. Hypertension and Cognitive Functioning. Hypertension. 2012 Aug 1;60(2):260-8.

5. Kodl CT, Seaquist ER. Cognitive dysfunction and diabetes mellitus. Endocrine reviews. 2008 Apr 24;29(4):494-511. 